\title{
Studies on Bio-ethanol Production Using Fermentation by Free and Immobilized Yeast Cells
}

\author{
Manasa P, Narasimhulu Korrapati* and Paramjeet Saroj
}

Department of Biotechnology, National Institute of Technology Warangal, Telangana, India.

\section{ABSTRACT}

Background: Production of bioethanol from yeast cells is very important to meet the energy crisis and this work mainly concentrated on bioethanol production by free and immobilized yeast cells.

Methods: Batch fermentation with free and immobilized yeast cells was done and compared.

Result: The maximum concentration of ethanol was reached around $48 \mathrm{~h}$ which was $30.02 \mathrm{gL}-1$ and 28.78 gL-1 for S.cerevisiae and Baker's yeast respectively. The maximum ethanol concentrations for each sets were 30.5 gL-1, 27.6 gL-1, and 28.2 gL-1 for subsequent sets of immobilized S.cerevisiae and $28.2 \mathrm{gL}-1,27.6 \mathrm{gL}-1$, and $26.98 \mathrm{gL}-1$ for subsequent sets of immobilized baker's yeast

Conclusion: As the total time for immobilized cells experiments was 3 sets of $56 \mathrm{~h}$ each or $168 \mathrm{~h}$, it shows the stability of cells and longer functional period. However, as the ethanol concentration was stagnant after $8 \mathrm{~h}$, one must reduce the time period of set readings to $4 \mathrm{~h}$ or $6 \mathrm{~h}$. However, the maximum ethanol concentration was observed after $48 \mathrm{~h}$ from the inoculation of the culture in all the cases which shows a promising time period to be targeted industrially. In conclusion, the immobilized cells have significant advantage over free cells using sodium alginate as the immobilizing agent. More research focused on the size, cell density and industrial scale studies using packed bed or tubular reactor must be done to analyze it better.

Keywords: Immobilized Cells, Fermentation, Recyclability, Alginate, Bioethanol, Glucose.

\section{Introduction}

Industrial revolution lead to use of machines and fuel. In recent years, the energy demand of any country is used to evaluate the development index. Presently, the major source fuel is fossils. The depletion of fossil fuels at an alarming rate is one of the major problems. Whereas being limited, fossil fuel are not environment friendly. To meet the ever increasing demand of energy while keeping in mind the environmental pollution, other sources, including solar and bioenergy such as, biomass, biogas and biofuel are being explored. In liquid fuels, ethanol, is identified as one of the best alternative. Useful as an environmental friendly additive for gasoline, ethanol is also easily produced by fermentation. Further, containing $35 \%$ oxygen, no particulate pollution and higher fuel combustion is obtained by ethanol. Being referred to as alternative oil and renewable energy source, studies on production of ethanol are important $[1,2,3,4,5,6]$.

Ethanol production is mainly done using microbes which ferment sugars. The sugars include hexoses such as glucose, mannose, xylose and galactose. Saccharomyces cerevisiae, a yeast is one of the easiest available and widely studied microbe. It is a highly effective bioethanol producing organism by fermentation of hexose sugars, especially glucose. With an ability of grow in relatively low $\mathrm{pH}$, the chances of contamination are also reduced. Further, high tolerance to ethanol concentration other inhibitory compounds adds on to its ability of being an ideal bioethanol producer [7]. S. cerevisiae mainly utilizes glucose as the course of carbon and metabolizes the same for the production of bioethanol. In this study, we used only native strains. Being a native strain, it is unable to metabolize xylose and only glucose fermentation was analyzed $[8,9]$.

Free cells are referred to as the broth culture. A major limitation of using free cells for fermentation is the lack of re-usability. A different approach of immobilizing cells have been reported widely. Immobilizing is done either using agar, or other polymers. A few of the main advantages of using immobilized cells are higher density of cells for every volume of the reaction mixture, easily separable from the reaction mixture hence increasing the chances of reusability, inhibition of cell loss during downstream and other flow operations, early achievement of exponential phase, high conversion rate of substrate, not affected by inhibitory molecules, more yield in lesser duration, better control over biomass growth [10]. A number of studies have reported the advantage of using immobilized cells for fermentation. With higher production as compared to free cells, the immobilized cells provide an economical 
alternative to free cells technique. With promising results in industrial applications, many different methods for immobilizing have been reported. [11, 12, 13]. The technique of using alginate to obtain immobilized cell's beads is economical, easy to obtain, and can be easily carried out at room temperature and mild conditions [14].

In this study, we used the method of immobilizing using alginate to obtain beads of desired cells and compared the ethanol fermentation of free cells with that of immobilized beads. Further, we also established the recyclability of alginate beads observing the fermentation for three sets.

\section{Materials and Methods}

Microorganisms: Baker's Yeast and Saccharomyces cerevisiae were used as microorganisms.

Chemicals: Glucose, Potassium dichromate, calcium chlorite, sodium alginate, sulfuric acid, Ethanol were used in the experimental work.

Biological Media: Yeast peptone broth and yeast fermentation broth were prepared and used in the work.

Glassware: Erlenmeyer flasks, Test tubes, Measuring cylinder, petri dish, funnel were used.

Other Equipments: Syringe filter, syringe ( $2 \mathrm{~mm})$, filter paper, falcon tubes, UV Spectrophotometer, cuvettes, Shaking Incubator, LAF, Eppendorf tubes, Centrifuge, Micropipettes were used.

Mother Culture: Obtained by streaking on YPD Agar plate

Growing Medium: The yeast cells were grown in a sterile solution $\left(121^{\circ} \mathrm{C}, 15 \mathrm{~min}\right.$.) containing $20 \mathrm{gL}^{-1}$ glucose, 20 $\mathrm{gL}^{-1}$ peptone, and $10 \mathrm{gL}^{-1}$ yeast extract, $\mathrm{pH} 5$. After $24 \mathrm{~h}$. at $25-30^{\circ} \mathrm{C}$, the mixture was centrifuged $(8000 \mathrm{rpm}, 10 \mathrm{~min}$.) and suspended in sterile water $(0.10 \mathrm{~L})$.

Fermentation Medium with Glucose: A sterile solution $\left(121^{\circ} \mathrm{C}, 20 \mathrm{~min}\right.$.) was prepared with $180 \mathrm{gL}^{-1}$ glucose, Yeast Nitrogenous Base $1.7 \mathrm{gL}^{-1}$, ammonium sulfate $5 \mathrm{gL}^{-}$ ', and $2.5 \mathrm{gL}^{-1}$ yeast.

Sodium Alginate Beads for Immobilization: For the immobilization in beads, 4\% (w/v) sodium alginate was dissolved in $0.10 \mathrm{~L}$ water and added to a $0.10 \mathrm{~L}$ suspension of $\mathrm{S}$. cerevisiae in a falcon. The solution was mildly shaken. $\mathrm{A} \mathrm{CaCl}_{2}$ solution with a final concentration of $1.3 \%(\mathrm{w} / \mathrm{v})$ was prepared in a separate beaker. The mixture containing the cells and the sodium alginate was added dropwise to $0.150 \mathrm{~L}$ of the $\mathrm{CaCl}_{2}$ solution using a $0.05 \mathrm{~L}$ syringe. The beads were hardened in this solution overnight at $4^{\circ} \mathrm{C}$. After hardening in the $\mathrm{CaCl}_{2}$ solution, the beads were rinsed with sterile water to be used thereafter in the fermentation experiments. The beads obtained had a diameter approximately between 3 to $5 \mathrm{~mm}$.

Batch Fermentation Experiments Using Free Cells: An experiment using free cells for the fermentation was carried out using the overnight grown yeast cells. The overnight grown cells were suspended in $100 \mathrm{~mL}$ yeast fermentation media and allowed for fermentation. The fermentation was carried out at $25-30^{\circ} \mathrm{C}$ at $120 \mathrm{rpm}$. Samples were collected for every $8 \mathrm{~h}$. to calculate the ethanol concentration.

\section{Batch Fermentation Experiments using the Immobilized} Cells

Approximately $25 \mathrm{~g}$ of calcium alginate beads was added to a $100 \mathrm{~mL}$ Erlenmeyer flask containing $50 \mathrm{~mL}$ of the fermentation medium with glucose in the yeast fermentation media. All steps prior to fermentation were carried out under LAF. The flasks were placed in an orbital shaker for $25-30^{\circ} \mathrm{C}$ and $100 \mathrm{rpm}$. Samples were collected every $8 \mathrm{~h}$. During the fermentation period. After $56 \mathrm{~h}$, the beads were filtered and rinsed with sterile water and added to a fresh yeast fermentation medium. The procedure was repeated two times for the successive fermentation cycles and reading were observed and tabulated.

Analytical Methods: Ethanol concentration was determined using Di-chromate method as described by Seo et al. [15]. TBP [tri-n-butyl phosphate] was used to extract ethanol in an aqueous solution; $1.5 \mathrm{ml}$ of TBP, and $1.5 \mathrm{ml}$ of an ethanol standard solution or sample were mixed in a test tube and then vortexed vigorously $20 \mathrm{~min}$. After phase separation, $1 \mathrm{ml}$ of the solvent phase (upper layer) was transferred to a $2 \mathrm{ml}$ Eppendorf tube. The dichromate reagent (equal volume $=1 \mathrm{ml}$ ) was then added, and then vortexed vigorously for $20 \mathrm{~min}$. After phase separation, $750 \mu \mathrm{l}$ of the dichromate reagent-containing lower phase was used to measure the OD at $595 \mathrm{~nm}$.

\section{Results and Discussion}

Batch Fermentation with Free Cells: Batch fermentation was carried out for Baker's yeast and S.cerevisiae with $180 \mathrm{gL}^{-1}$ of glucose in triplicates with $100 \mathrm{ml}$ each. The concentration of ethanol was observed after $24 \mathrm{~h}$ of growth. The fermentation was observed for $160 \mathrm{~h}$. For every $8 \mathrm{~h}$, $1.5 \mathrm{ml}$ of media was collected and analyzed for ethanol concentration and tabulated as Table 1 and Table 2. As shown in the Fig 1 and Fig 2, the maximum concentration of ethanol was reached around $48 \mathrm{~h}$ which was $30.02 \mathrm{gL}^{-1}$ and $28.78 \mathrm{gL}^{-1}$ for S.cerevisiae and Baker's yeast respectively. Further, as the graph shows, the concentration of ethanol was roughly constant after $48 \mathrm{~h}$ only varying with the lower range of $3.9 \mathrm{gL}^{-1}$ and $1.8 \mathrm{gL}^{-1}$ for S.cerevisiae and Baker's yeast respectively. The results are comparable to studies 
[15]. The graph also shows the production of ethanol is constant which suggest that the maximum concentration is reached at the end of the exponential phase itself. The constant region may highlight the stationary phase. The results suggested to focus on the first half of the time period or roughly $40-50 \mathrm{~h}$ for obtaining the maximum concentration of ethanol on industrial scale.

Batch Fermentation with Immobilized Cells: The immobilized cells were obtained using sodium alginate beads which had a diameter of 3-5mm. Each fermentation media had a glucose concentration of $180 \mathrm{gL}^{-1}$. Three sequential fermentation cycles were carried out to observe the recyclability of the immobilized cells. Each fermentation set was observed for $56 \mathrm{~h}$. For every 8h, $1.5 \mathrm{ml}$ of media was collected and analyzed for ethanol concentration and tabulated as Table 3 and Table 4.

The maximum ethanol concentrations for each sets were $30.5 \mathrm{gL}^{-1}, 27.6 \mathrm{gL}^{-1}$, and $28.2 \mathrm{gL}^{-1}$ for subsequent sets of immobilized S.cerevisiae and $28.2 \mathrm{gL}^{-1}, 27.6 \mathrm{gL}^{-1}$, and $26.98 \mathrm{gL}^{-1}$ for subsequent sets of immobilized baker's yeast as shown in Fig 3 and Fig 4. This maximum ethanol concentration was slightly different when compared to free cells which may be due to diffusional barriers, however, interestingly the difference was not significant. This may lead to inhibition of nutrients to some cells especially at the center of the beads leading to inefficient fermentation. However, this drawback can be removed by reduced sixe of beads which increases the surface area for effective contact with the media.

The concentration of ethanol in the fermentation media changed marginally during the observed time of exposure to alginate beads. This suggests that in each fermentation set, the immobilized yeast cells were in their stationary phase. Further, the concentration declined after each set of use suggesting loss of efficiency in subsequent steps.

Table 1: Ethanol concentration values for S.cerevisiae

\begin{tabular}{|c|c|}
\hline \multicolumn{2}{|c|}{ Time(h) } \\
\hline 0 Ethanol Concentration(gL-1) & 0 \\
\hline 20.61795 & 32 \\
\hline 25.55345 & 40 \\
\hline 26.48444 & 48 \\
\hline 30.02154 & 56 \\
\hline 28.1654 & 64 \\
\hline 27.9582 & 72 \\
\hline 27.20162 & 80 \\
\hline 27.95662 & 88 \\
\hline 28.65 & 96 \\
\hline 27.30988 & 104 \\
\hline 27.4526 & 112 \\
\hline 27.62651 & 120 \\
\hline 26.92016 & 128 \\
\hline 26.12548 & 136 \\
\hline 27.9995 & 144 \\
\hline 27.36401 & 152 \\
\hline 27.1365 & 160 \\
\hline 27.92963 & \\
\hline
\end{tabular}

Table 2: Ethanol concentration values for Baker's yeast

\begin{tabular}{|c|c|}
\hline Ethanol Concentration $\left(\mathbf{g L}^{-1}\right)$ & Time(h) \\
\hline 0 & 24 \\
\hline 22.11907984 & 32 \\
\hline 23.7822 & 40 \\
\hline 25.698 & 48 \\
\hline 28.77852954 & 56 \\
\hline 28.00012 & 64 \\
\hline 27.86969 & 72 \\
\hline 27.97789806 & 80 \\
\hline 27.30987821 & \\
\hline
\end{tabular}


Ethanol Concentration $\left(\mathrm{gL}^{-1}\right)$

Time(h)

\begin{tabular}{|c|c|}
\hline 28.00085 & 88 \\
\hline 28.08840776 & 96 \\
\hline 28.00054 & 104 \\
\hline 28.311 & 112 \\
\hline 28.06630582 & 120 \\
\hline 26.92016238 & 128 \\
\hline 28.16589 & 136 \\
\hline 27.99956 & 144 \\
\hline 28.35466 & 152 \\
\hline 28.77852954 & 160 \\
\hline
\end{tabular}

Table 3: Ethanol concentration for immobilized alginate beads of S.cerevisiae

\begin{tabular}{|c|c|c|c|} 
& Ethanol Concentration $\left(\mathbf{g L}^{-1}\right)$ & Set 2 & Time (h) \\
Set 3 & & 0 \\
\hline 0 & Set 1 & 0 & 24.722 \\
\hline 8 & 0 & 24.6365 & 25.845 \\
\hline 16 & 25.69 & 25.9586 & 23.151 \\
\hline 24 & 26.54 & 26.6969 & 28.201 \\
\hline 32 & 27.6 & 27.3621 & 25.015 \\
\hline 40 & 30.5214 & 27.64 & 26.908 \\
\hline 56 & 28.635 & 27.145 & 25.652 \\
\hline
\end{tabular}

Table 4: Ethanol concentration for immobilized alginate beads of Baker's Yeast

\begin{tabular}{|c|c|c|c|} 
& $\begin{array}{c}\text { Ethanol Concentration (gL-1) } \\
\text { Set 1 }\end{array}$ & Set 2 & Time (h) \\
Set 3 & 0 \\
\hline 0 & 0 & 0 & 25.215 \\
\hline 8 & 25.66 & 25.3114 & 23.013 \\
\hline 16 & 25.648 & 24.9895 & 26.01 \\
\hline 24 & 26.482 & 26.324 & 26.98 \\
\hline 40 & 27.99519 & 27.6352 & 23.625 \\
\hline 48 & 28.2152 & 24.6528 & 25.1 \\
\hline 56 & 27.86969 & 26.512 & 24.685 \\
\hline
\end{tabular}

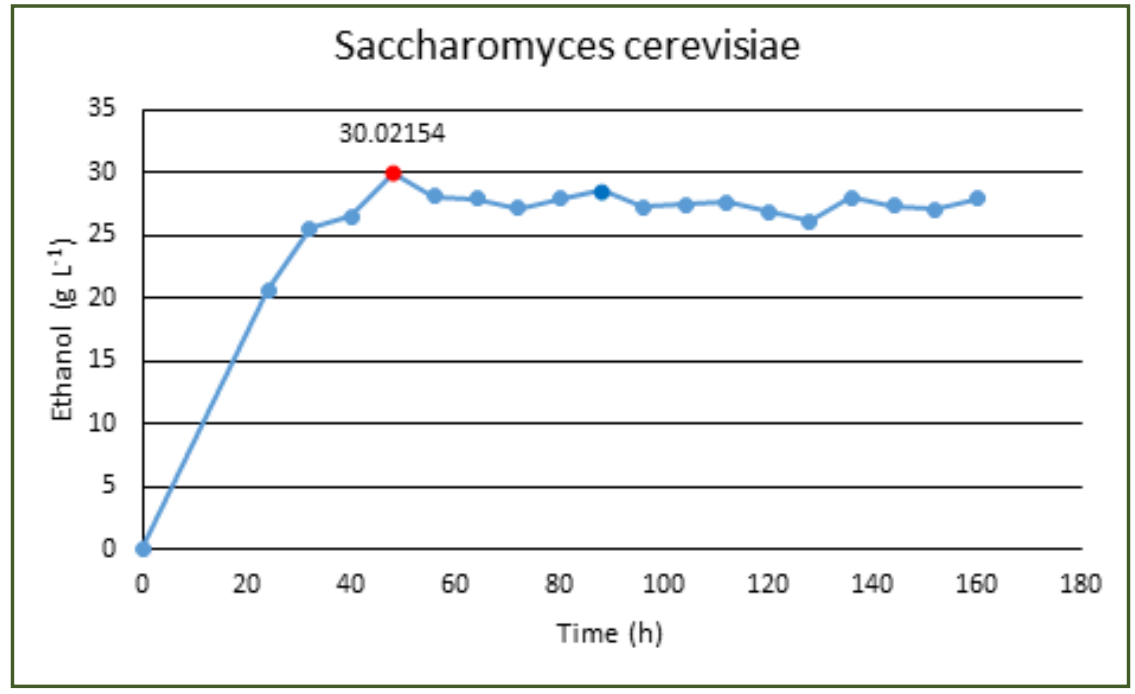

Fig. 1: Ethanol concentration for S.cerevisiae free cells.

http://www.pacificejournals.com/aabs 


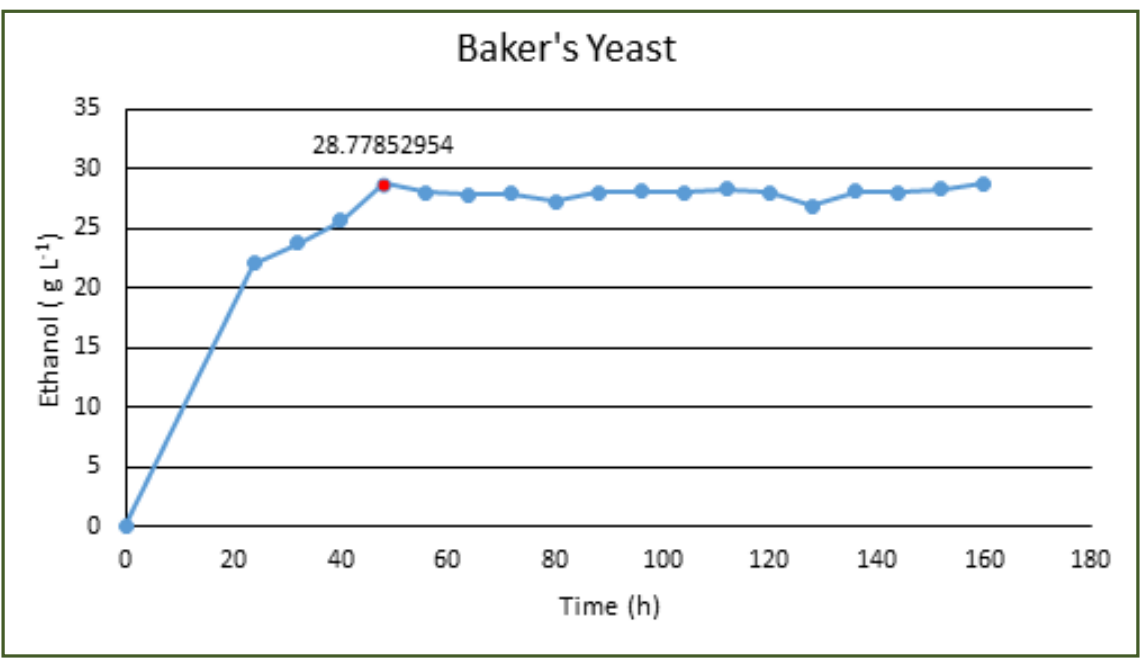

Fig. 2: Ethanol concentration for Baker's Yeast free cells.

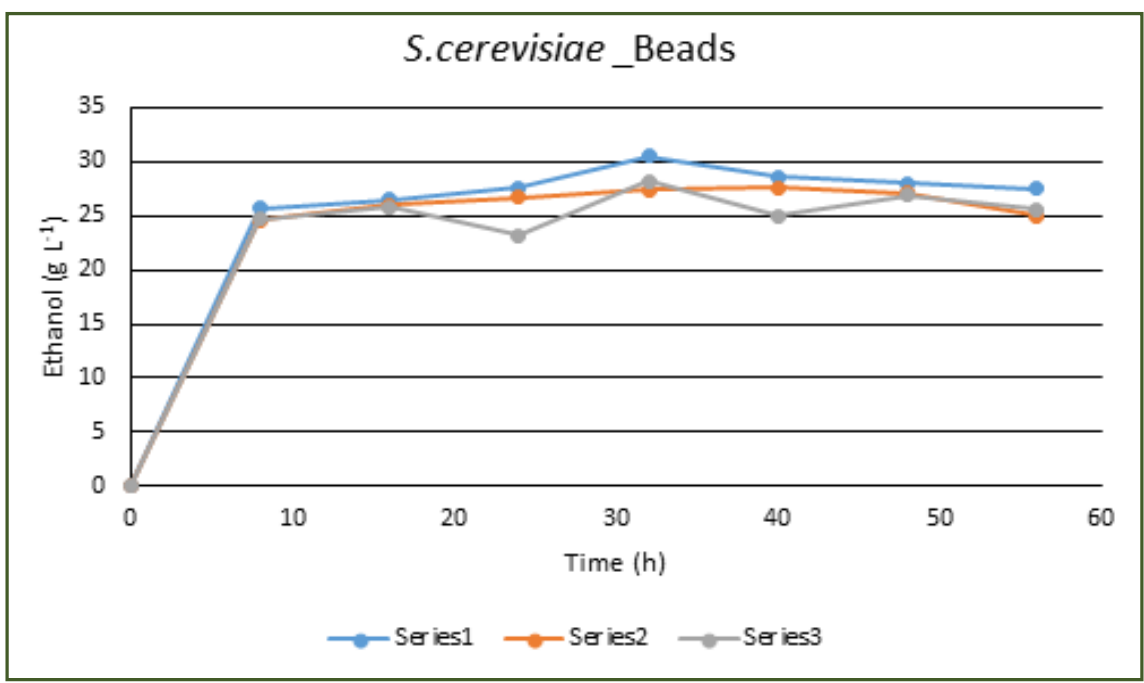

Fig. 3: Fermentation cycles for immobilized alginate beads of S.cerevisiae.

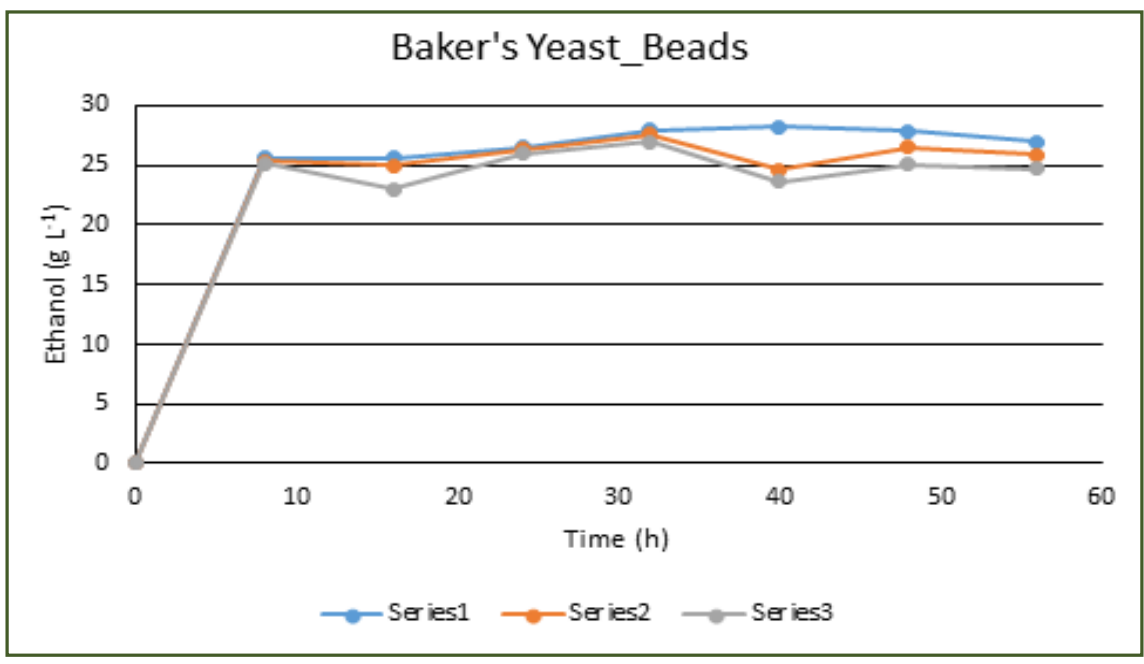

Fig. 4: Fermentation cycles for immobilized alginate beads of Baker's Yeast 


\section{Conclusion}

Immobilizing the cells in sodium alginate beads provide several advantages. Such as easy separation, recyclability, control on biomass being used, total duration and most importantly, much lower cost. Moreover, as observed in our experiments, no significant difference can be established between free and immobilized cells. It can be said that even though diffusional barriers might exist, proper agitation, bead size and cell concentration can lead to similar ethanol production from both free and immobilized cells. A major challenge tackled with immobilization is removal of contamination as all experiments were done in sterile conditions. As the total time for immobilized cells experiments was 3 sets of 56 $\mathrm{h}$ each or $168 \mathrm{~h}$, it shows the stability of cells and longer functional period. However, as the ethanol concentration was stagnant after $8 \mathrm{~h}$, one must reduce the time period of set readings to $4 \mathrm{~h}$ or $6 \mathrm{~h}$. However, the maximum ethanol concentration was observed after $48 \mathrm{~h}$ from the inoculation of the culture in all the cases which shows a promising time period to be targeted industrially. In conclusion, the immobilized cells have significant advantage over free cells using sodium alginate as the immobilizing agent. More research focused on the size, cell density and industrial scale studies using packed bed or tubular reactor must be done to analyze it better.

\section{Acknowledgements}

The authors thankful to the Director, National Institute of Technology, warangal for supporting to conduct this research.

\section{References}

1. FW, B., WA, A., \& M, M.-Y. (2008). Ethanol fermentation technologies from sugar and starch feedstocks. Biotechnol Adv, 26:89-105.

2. Y, L., \& S, T. (2006). Ethanol fermentation from biomass resources: Current state and prospects. Appl Microbiol Biot, 69:627-642.
3. C, L., F, W., \& F, O.-Y. (2009). Ethanol fermentation in a magnetically fluidized bed reactor with immobilized Saccharomyces cerevisiae in magnetic particles. Bioresource Technol, 100:878-882.

4. A, R., S, L., \& M, P. (2011). Ethanol production by repeated batch and continuous fermentations of blackstrap molasses using immobilized yeast cells on thin-shell silk cocoons. Appl Energ, 88:4400-4404.

5. Martinez, D., \& Ebenhack, B. (2008). Energy Policy 36. 1430-1435.

6. P.C. Badger. (2002). Ethanol from Cellulose: A General Review. Trends in New Crops and New Uses, pp. 17-21.

7. L, O., \& J, N. (2000). The role of metabolic engineering in the improvement of Saccharomyces cerevisiae: utilization of industrial media. Enzyme Microb Tech , 26:785-792.

8. PY, W., \& H, S. (1980). Growth of yeasts on D-xylulose. Can J Microbiol, 26:1165-1168.

9. PY, W., C, S., \& H, S. (1980). Fermentation of a pentose by yeasts. Biochem Biophys Res Commun, 94:248-254.

10. R, W., A, F., PJS, M., JAR, R., E, T., \& K, A. (2001). Continuous fermentation of sugar cane syrup using immobilized yeast cells. J Biosci Bioeng, 91:48-52.

11. Y, L., \& S, T. (2006). Ethanol fermentation from biomass resources: Current state and prospects. Appl Microbiol Biot, 69:627-642

12. DS, I., DP, T., SN, C., AS, M., \& CR, R. (1983). Ethanol production by $\mathrm{S}$. cerevisiae immobilized in hollow-fiber membrane bioreactors. Appl Environ Microb, 46:264-278.

13. W, Y., X, W., J, Z., B, S., YY, Z., \& C, M. (2011). Bacterial cellulose membrane - A new support carrier for yeast immobilization for ethanol fermentation. Process Biochem, 46:2054-2058

14. Z, Z., G, L., \& Y, L. (2010). Immobilization of Saccharomyces cerevisiae alcohol dehydrogenase on hybrid alginate-chitosan beads. Int J Biol Macromol, 47:21-26.

15. Seo, H.-B., Kim, H.-J., Lee, O.-K., Ha, J.-H., Lee, H.-Y., \& Jung, K.-H. (2009). Measurement of ethanol concentration using solvent extraction and dichromate oxidation and its application to bioethanol production process. J Ind Microbiol Biotechnol , 36:285-292.

*Corresponding author:

Dr. Narasimhulu Korrapati, Department of Biotechnology, National Institute of Technology Warangal, Telangana-506004, India, Phone: +919985470286

Email:simha7762006@gmail.com 